Article

\title{
Investigation of Ytterbium Incorporation in Lithium Niobate for Active Waveguide Devices
}

\author{
Christian E. Rüter *, Dominik Brüske, Sergiy Suntsov and Detlef Kip \\ Faculty of Electrical Engineering, Helmut Schmidt University, 22043 Hamburg, Germany; \\ bruesked@hsu-hh.de (D.B.); suntsov@hsu-hh.de (S.S.); kip@hsu-hh.de (D.K.) \\ * Correspondence: ceh@hsu-hh.de
}

Received: 14 February 2020; Accepted: 11 March 2020; Published: 24 March 2020

Featured Application: Active waveguide devices, waveguide lasers.

\begin{abstract}
In this work, we report on an investigation of the ytterbium diffusion characteristics in lithium niobate. Ytterbium-doped substrates were prepared by in-diffusion of thin metallic layers coated onto $x$ - and $z$-cut congruent substrates at different temperatures. The ytterbium profiles were investigated in detail by means of secondary neutral mass spectroscopy, optical microscopy, and optical spectroscopy. Diffusion from an infinite source was used to determine the solubility limit of ytterbium in lithium niobate as a function of temperature. The derived diffusion parameters are of importance for the development of active waveguide devices in ytterbium-doped lithium niobate.
\end{abstract}

Keywords: thermal diffusion; active waveguide devices; laser active materials

\section{Introduction}

The ferroelectric crystal lithium niobate $\left(\mathrm{LiNbO}_{3}\right)$ is a well-known material for various optical applications due to its favorable electro-optical, acousto-optical, piezoelectric, and nonlinear properties. Furthermore, low-loss waveguides can be implemented in rare-earth-doped $\mathrm{LiNbO}_{3}$ via several fabrication techniques [1-6], leading to the development of waveguide amplifiers as well as waveguide lasers. In the past, a variety of efficient erbium- $(\mathrm{Er})$ and neodymium ( $\mathrm{Nd}$ )-doped $\mathrm{LiNbO}_{3}$ waveguide lasers have been realized [7-10]. Another attractive laser material is $\mathrm{Yb}: \mathrm{LiNbO}_{3}$. Due to the simple energy level scheme of ytterbium $(\mathrm{Yb})$ with only one excited state, a small laser quantum defect can be achieved, allowing for the development of highly efficient $\mathrm{Yb}$ lasers [11]. Another benefit of $\mathrm{Yb}$ is the large gain bandwidth, which allows for wide wavelength tuning and the generation of ultrashort pulses [12,13].

In 1995, Jones et al. reported the demonstration of an $\mathrm{Yb}: \mathrm{LiNbO}_{3}$ waveguide laser with a slope efficiency of $16 \%$ [14]. Due to photorefractive damage, the y-propagation Ti-diffused $\mathrm{Yb}: \mathrm{LiNbO}_{3}$ waveguide laser showed unstable laser operation. Later, Fujimura et al. reported continuous-wave lasing with a slope efficiency of $7 \%$ in z-cut $\mathrm{LiNbO}_{3}$ annealed/proton-exchanged (APE) waveguides [15] by using thermally in-diffused $\mathrm{Yb}$. While in the latter works, channel waveguides were used, another method which also reduces photorefractive damage is using ridge waveguides [16]. In such geometry, further improvement of the laser performance can be achieved due to the smaller mode fields and significantly improved overlap of optical pump and laser modes, when compared to their channel counterparts. Recently, a novel fabrication method has been reported comprising ridge definition by diamond blade dicing followed by three-side $\mathrm{Er} / \mathrm{Nd}$ and $\mathrm{Ti}$ in-diffusion for the development of highly efficient rare-earth-doped Ti: $\mathrm{LiNbO}_{3}$ ridge waveguide lasers [17-19]. This fabrication technique is a promising method for increasing the slope efficiency of $\mathrm{Yb}: \mathrm{LiNbO}_{3}$ waveguide lasers, too. For the development of low-loss $\mathrm{Yb}$ :Ti: $\mathrm{LiNbO}_{3}$ ridge waveguides with optimized overlap of the $\mathrm{Yb}$ doping 
profile and the intensity profiles of the guided modes, it is essential to know the diffusion constants and the maximum solubility of $\mathrm{Yb}$ in $\mathrm{LiNbO}_{3}$. Apart from a single value for the diffusivity at $1100{ }^{\circ} \mathrm{C}$ in z-direction [20], only a few data regarding the diffusion doping of $\mathrm{LiNbO}_{3}$ with $\mathrm{Yb}$ can be found [14,21].

In this work, we report on an investigation of the incorporation of $\mathrm{Yb}$ into $\mathrm{LiNbO}_{3}$ by in-diffusion. To determine the diffusion constants and the maximum solubility of $\mathrm{Yb}$ in $\mathrm{LiNbO}_{3}$, diffusion profiles measured by SNMS (secondary neutral mass spectrometry) were analyzed. With these data, a first ridge waveguide sample was prepared, and the absorption and emission spectra of the in-diffused $\mathrm{Yb}$ ions were measured and compared with literature values.

\section{Experimental Methods}

\subsection{Sample Preparation}

For the sample fabrication, optical-grade $\mathrm{x}$ - and z-cut wafers of congruent $\mathrm{LiNbO}_{3}$ (Yamaju Ceramics Co., LTD) were used. Pieces of $10 \times 10 \times 1 \mathrm{~mm}^{3}$ were prepared by diamond saw dicing. The samples were cleaned using successive baths of acetone, isopropanol and deionized water, and an ultrasonic cleaner. Plasma cleaning in oxygen was applied as the final cleaning step prior to vacuum deposition. The samples were coated with $20 \mathrm{~nm}$ thick layers of $\mathrm{Yb}$, with a purity of $99.9 \%$, using electron beam evaporation. For annealing, the samples were placed in a platinum crucible in a high temperature elevator furnace for diffusion time of $30 \mathrm{~h}$ at different temperatures between 930 and $1130^{\circ} \mathrm{C}$. The heating and cooling rates were constant for all samples.

One sample with dimensions of $1 \times 25 \times 8 \mathrm{~mm}^{3}$ (x y z) from the $\mathrm{x}$-cut wafer was also used to prepare $\mathrm{Yb}$-doped ridge waveguides. For this, ridges were prepared in the $\mathrm{x}$ surface running parallel to the $\mathrm{y}$-axis by precise diamond blade milling, and these samples were coated with $22 \mathrm{~nm}$ of $\mathrm{Yb}$ under symmetric angles of $\pm 60^{\circ}$. For diffusion, the coated ridges were annealed at $T=1125^{\circ} \mathrm{C}$ for $t=216 \mathrm{~h}$. Afterwards, $85 \mathrm{~nm}$ of Ti were deposited under symmetric angles of $\pm 60^{\circ}$ and in-diffused to prepare the ridge waveguides as described in [17].

\subsection{SNMS Measurements}

The SNMS measurements were performed using the Multimethod System with INA-X from SPECS. For the direct bombardment mode during sputtering, an RF-excited Krypton plasma was used. Samples were protected by a copper mask defining a free area with a diameter of $5 \mathrm{~mm}$ in the central part of each sample. After SNMS analysis, the sputtered crater was measured using a white light interferometer (WLI from FRT) to determine the sputtering rate. The rate was $(0.45 \pm 0.02) \mathrm{nm} / \mathrm{s}$ for all samples.

\section{Results and Discussion}

Figure 1 shows the depth profiles of ${ }^{7} \mathrm{Li},{ }^{93} \mathrm{Nb},{ }^{16} \mathrm{O}$, and ${ }^{70} \mathrm{Yb}$ on a semilogarithmic scale giving two examples of SNMS spectra of the $\mathrm{Yb}$-doped $\mathrm{LiNbO}_{3}$ samples used in this analysis. Figure $1 \mathrm{a}$ demonstrates that at lower temperatures, a certain amount of $\mathrm{Yb}$ remains in form of a thin film on the surface, indicating that the $\mathrm{Yb}$ reservoir has not been exhausted.

\section{Diffusion Theory}

The $\mathrm{Yb}$ concentration profiles obtained in this work can be well approximated utilizing the one-dimensional diffusion theory described by Fick's second law of diffusion.

$$
\frac{\partial C}{\partial t}=D \frac{\partial^{2} C}{\partial y^{2}}
$$

where $D$ is the diffusion coefficient and $y$ quantifies the direction normal to the surface. Assuming an inexhaustible source (i.e., a thick film) of $\mathrm{Yb}$ on the surface, the solution of Fick's law (1) can be approximated by 


$$
C(y)=C_{\max } \operatorname{erfc}\left(y / d_{\text {erf }}\right),
$$

with $C_{\max }$ being the concentration of $\mathrm{Yb}$ at the crystal surface and the diffusion depth $d_{\text {erf }}=\sqrt{4 D t}$. In the thick-film diffusion regime. $C_{\max }$ describes the solubility of $\mathrm{Yb}$ in $\mathrm{LiNbO}_{3}$. This value is given by

$$
C_{\max }=\sqrt{\frac{\pi}{4 D t}} \int_{0}^{\infty} C(y) d y .
$$

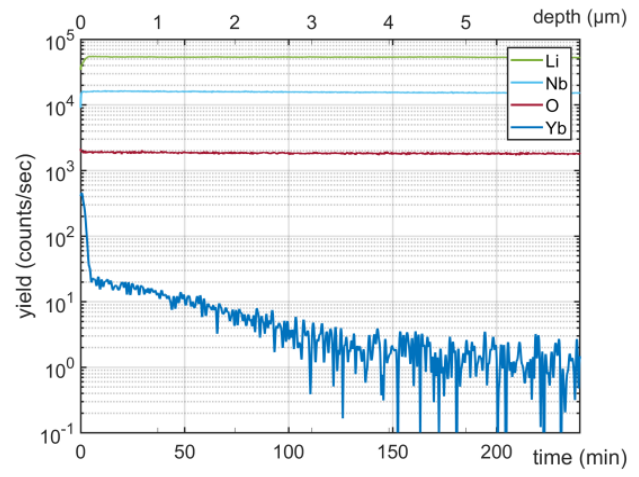

(a)

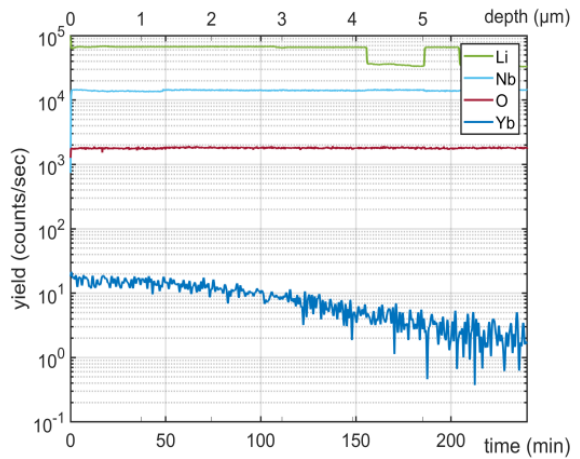

(b)

Figure 1. Secondary neutral mass spectrometry (SNMS) spectra of $\mathrm{x}$-cut $\mathrm{Yb}: \mathrm{LiNbO}_{3}$. The two samples were coated with $20 \mathrm{~nm} \mathrm{Yb}$, and the diffusion parameters are $(\mathbf{a}) \mathrm{T}=1060^{\circ} \mathrm{C}, t=30 \mathrm{~h}$ and $(\mathbf{b}) \mathrm{T}=1130^{\circ} \mathrm{C}$, $t=30 \mathrm{~h}$, respectively.

Using the law of mass conservation, the time needed for the $\mathrm{Yb}$ source to be depleted can be calculated with the metallic $\mathrm{Yb}$ density $\rho$, the atomic mass $m_{\mathrm{Yb}}$, and the thickness $\tau$ of the initial $\mathrm{Yb}$ layer

$$
t_{d}=\left(\frac{\rho \tau}{2 m_{Y b} C_{\max }}\right)^{2} \frac{\pi}{D} .
$$

For sufficiently thin films and/or sufficiently long in-diffusion times $\left(t>t_{d}\right)$, the $\mathrm{Yb}$ source is depleted and the diffusion profile can be approximated by a Gaussian function

$$
C(y)=C_{0} \exp \left(-\frac{y^{2}}{d_{\exp }^{2}}\right) .
$$

In this case, $d_{\exp }=\sqrt{4 D t}$ describes the 1/e-depth of the profile. The surface concentration $C_{0}$ is below the solubility and given by

$$
C_{0}=\frac{\tau C_{\max }}{\sqrt{\pi D t}} .
$$

The temperature dependence of the diffusion coefficient $D$ is given by the Arrhenius relation

$$
D(T)=D_{0} \exp \left(-\frac{E_{A}}{k_{B} T}\right) .
$$

Here, $D_{0}$ is the diffusion constant, $E_{A}$ the activation energy, $k_{B}$ the Boltzmann constant, and $T$ is the temperature used for in-diffusion.

As the solubility describes the equilibrium between $\mathrm{Yb}$ in $\mathrm{LiNbO}_{3}$ and the pure metallic $\mathrm{Yb}$ on the surface, the concentration at the surface can also be written in terms of an Arrhenius-type equation as

$$
C_{\max }(T)=\hat{C} \exp \left(-\frac{\Delta H}{k_{B} T}\right),
$$

where $\Delta H$ is the mixing enthalpy and $\hat{C}$ is a pre-factor. 
Figure 2 shows the high-resolution images of the crystal surfaces obtained using a confocal microscope and applying the differential interference contrast method for the two crystal orientations. When the temperature used for annealing is less than $1130{ }^{\circ} \mathrm{C}$, an increased surface roughness caused by insufficient diffusion is visible. For the x-cut surfaces, the arithmetical mean height $(\mathrm{Sa} a$ slightly decreases from 12 to $10 \mathrm{~nm}$ when the temperature increases from (a) 1000 to (b) $1060{ }^{\circ} \mathrm{C}$.

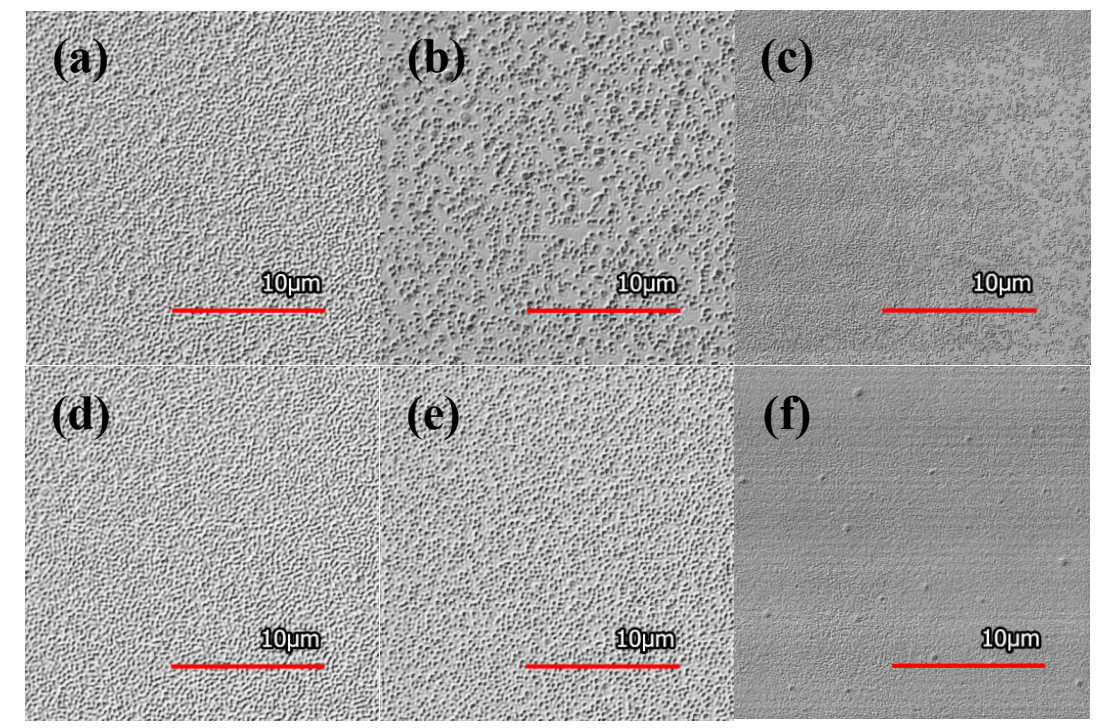

Figure 2. Confocal microscope images of $\mathrm{LiNbO}_{3}$ surfaces coated with $20 \mathrm{~nm}$ thick $\mathrm{Yb}$ films after annealing for $30 \mathrm{~h}$. Results for x-cut surfaces annealed at (a) 1000, (b) 1060, and (c) $1130{ }^{\circ} \mathrm{C}$; results for z-cut surfaces annealed at (d) 1000, (e) 1060, and (f) $1130{ }^{\circ} \mathrm{C}$.

For the z-cut surface shown in (d) and (e), the $S a$ is reduced from 11 to $7 \mathrm{~nm}$. Annealing for $30 \mathrm{~h}$ at $1130{ }^{\circ} \mathrm{C}$ results in a smooth surface with $S a=2 \mathrm{~nm}$ for both (c) $\mathrm{x}$ - and (f) z-cut surfaces, indicating that the $\mathrm{Yb}$ ion source at the surface is completely exhausted, and the $\mathrm{Yb}$ profile can be described by the thin-film diffusion regime of Equation (5).

For calibration of the SNMS data, the samples annealed at $1130^{\circ} \mathrm{C}$ were used assuming a linear relation between ion yield and concentration as well as mass conservation in the diffusion process. For lower temperatures, the experimentally obtained profiles can be best fitted by complementary error functions, as can be seen in Figure 3.

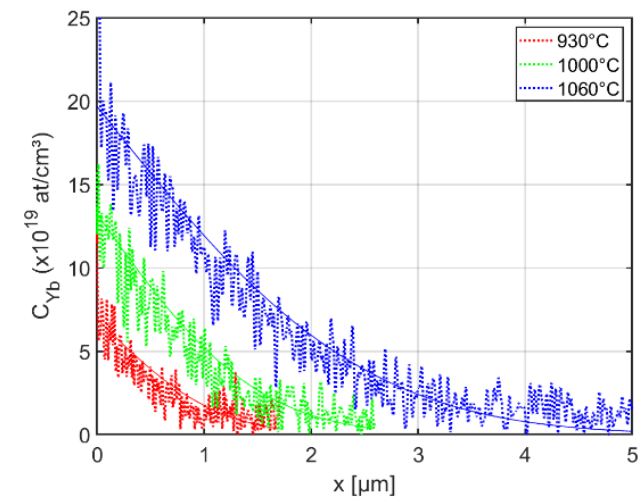

(a)

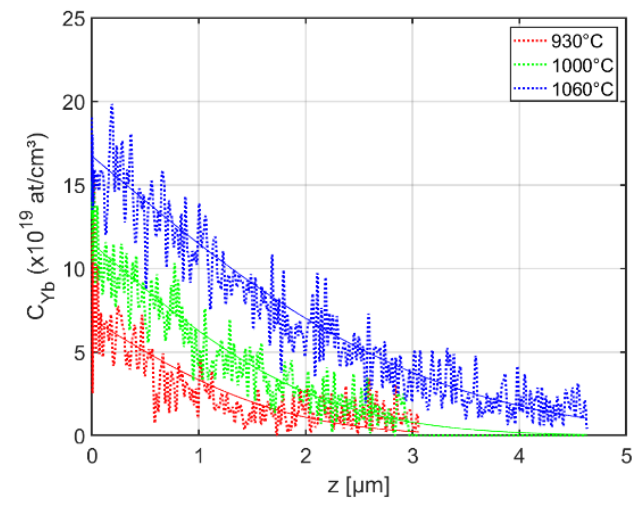

(b)

Figure 3. SNMS depth profiles of $\mathrm{Yb}$ in $\mathrm{LiNbO}_{3}$ for in-diffused layers with an initial thickness of $20 \mathrm{~nm}$ annealed for $30 \mathrm{~h}$ at different temperatures for (a) $\mathrm{x}$-cut and (b) $\mathrm{z}$-cut substrates. The dotted lines show the measured profiles and the solid lines indicate complementary error function fits. 
The profiles obtained using the highest temperature were fitted by Gaussian functions; see Figure 4 . The results obtained for the surface concentration and for the depths $d_{\text {erf }}$ or $d_{\text {exp }}$ are summarized in Table 1.

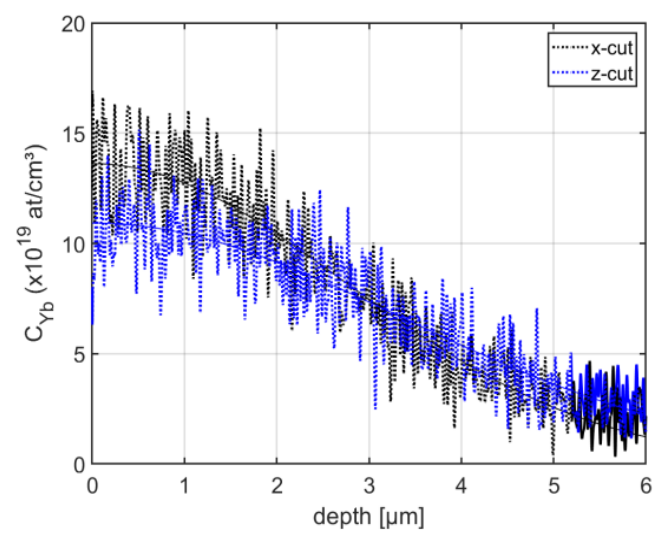

Figure 4. SNMS depth profiles of $\mathrm{Yb}$ in $\mathrm{LiNbO}_{3}$ for in-diffused layers with an initial thickness of $20 \mathrm{~nm}$ annealed for $30 \mathrm{~h}$ at $1130{ }^{\circ} \mathrm{C}$ for different cut directions.

Table 1. Parameters obtained for the $\mathrm{Yb}$ diffusion in $\mathrm{LiNbO}_{3}$.

\begin{tabular}{|c|c|c|c|c|c|}
\hline $\begin{array}{c}\text { Temperature } \\
\left({ }^{\circ} \mathrm{C}\right)\end{array}$ & Time (h) & $\begin{array}{c}C_{0} \times 10^{19} \\
\left(\text { ions } / \mathrm{cm}^{3}\right)\end{array}$ & $\begin{array}{c}C_{\max } \times 10^{19} \\
\left(\text { ions } / \mathrm{cm}^{3}\right)\end{array}$ & $d_{\mathrm{erf}}(\mu \mathrm{m})$ & $d_{\exp }(\mu \mathrm{m})$ \\
\hline \multicolumn{6}{|l|}{ z-cut } \\
\hline 930 & 30 & $6.96 \pm 0.10$ & & $1.99 \pm 0.13$ & \\
\hline 1000 & 30 & $11.53 \pm 0.09$ & & $2.32 \pm 0.14$ & \\
\hline 1060 & 30 & $16.89 \pm 0.10$ & & $3.47 \pm 0.19$ & \\
\hline 1130 & 30 & & $10.94 \pm 0.05$ & & $4.68 \pm 0.26$ \\
\hline \multicolumn{6}{|l|}{ x-cut } \\
\hline 930 & 30 & $6.89 \pm 0.10$ & & $1.24 \pm 0.08$ & \\
\hline 1000 & 30 & $13.21 \pm 0.12$ & & $1.66 \pm 0.10$ & \\
\hline 1060 & 30 & $20.06 \pm 0.12$ & & $2.70 \pm 0.15$ & \\
\hline 1130 & 30 & & $13.62 \pm 0.06$ & & $3.84 \pm 0.21$ \\
\hline
\end{tabular}

With the values for the diffusion depth, the diffusion coefficients $D$ are calculated. The temperature dependence of the diffusion coefficient is given by Equation (7). Figure 5 shows the corresponding Arrhenius plots for the two crystal-cut directions used. By correlating the fitted lines with Equation (7), the values for the diffusion coefficients and the activation energy for the $x$ - and z-direction were obtained. The results are summarized in Table 2.

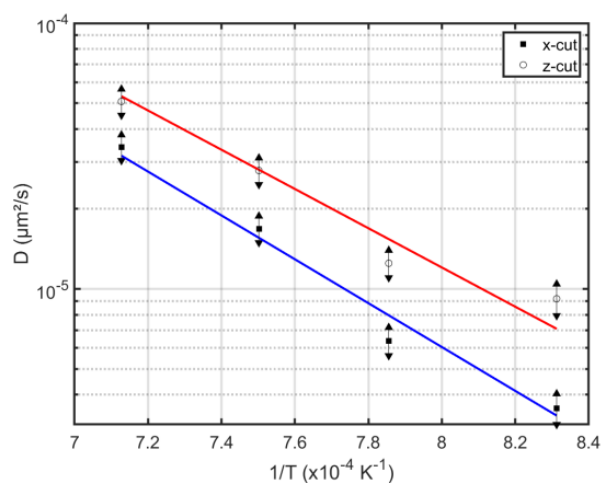

Figure 5. Arrhenius plot of the diffusion coefficients of $\mathrm{Yb}$ in $\mathrm{LiNbO}_{3}$ for diffusion parallel to the $\mathrm{x}$ - and z-axis. The fitted lines correspond to Equation (7). 
Table 2. Diffusion constants and activation energies for $\mathrm{Yb}$ diffusion in $\mathrm{LiNbO}_{3}$.

\begin{tabular}{lcc}
\hline & $\mathbf{D}_{\mathbf{0}}\left(\times \mathbf{1 0 ^ { - 8 }} \mathbf{c m}^{2} / \mathbf{s}\right)$ & $\mathbf{E}_{\mathbf{A}}(\mathbf{e V})$ \\
\hline Diffusion in z-direction & $9.7 \pm 0.8$ & $1.46 \pm 0.07$ \\
Diffusion in x-direction & $24.1 \pm 1.9$ & $1.64 \pm 0.07$ \\
\hline
\end{tabular}

The temperature dependence of the surface concentration is presented in Figure 6. As can be seen, the measured values for the surface concentration of $\mathrm{Yb}$ for the three lowest temperatures indicate that, in contrast to the diffusivity, the solubility of $\mathrm{Yb}$ in $\mathrm{LiNbO}_{3}$ shows no anisotropic behavior. The solid line is a fit to the data with Equation (8). This way, the values of $\Delta H=(1.04 \pm 0.23) \mathrm{eV}$ and $\hat{C}=(1.6 \pm 0.35) \times 10^{24} \mathrm{~cm}^{-3}$ were found.

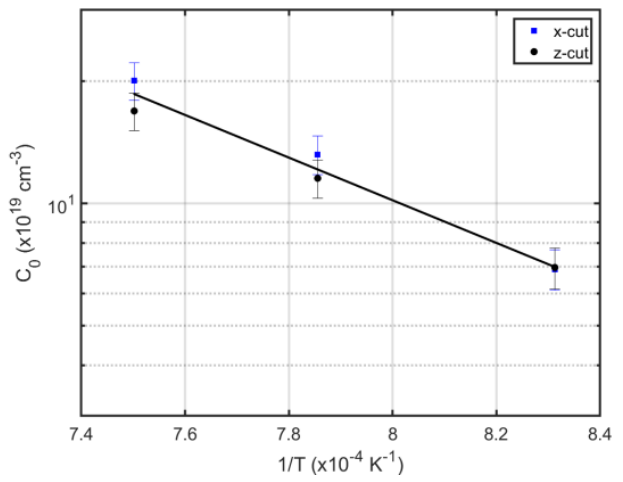

Figure 6. Arrhenius plot of the solubility data of $\mathrm{Yb}$ in $\mathrm{LiNbO}_{3}$. The line is a fit of the data using Equation (8).

With these characteristic values for the diffusion of $\mathrm{Yb}$ in $\mathrm{LiNbO}_{3}$, a first test was performed for diffusion doping of a ridge waveguide prepared in an $\mathrm{x}-\mathrm{cut} \mathrm{LiNbO}_{3}$ substrate oriented parallel to the $\mathrm{y}$-axis by diamond blade dicing. Figure $7 \mathrm{a}$ shows the simulated $\mathrm{Yb}$ concentration profile in the ridge for the case of two $22 \mathrm{~nm}$ thick $\mathrm{Yb}$ layers being coated under $\pm 60^{\circ}$ with respect to the $\mathrm{x}$-axis obtained by numerically solving Fick's second law. For in-diffusion, the sample is annealed for $216 \mathrm{~h}$ at $1125{ }^{\circ} \mathrm{C}$. The concentration profile also shows that at the upper right and left corners of the ridge, the expected concentration is below the solubility limit. Thus, no additional surface defects are to be expected. To achieve waveguiding, the upper part of the ridge is additionally doped by in-diffusion of Ti.

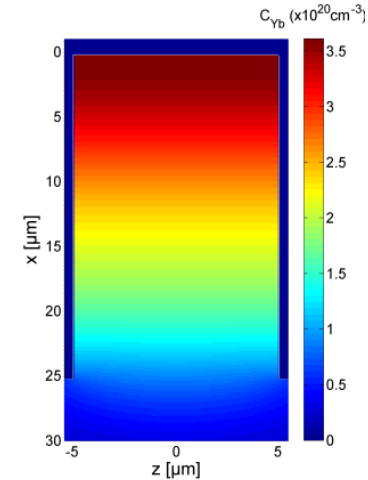

(a)

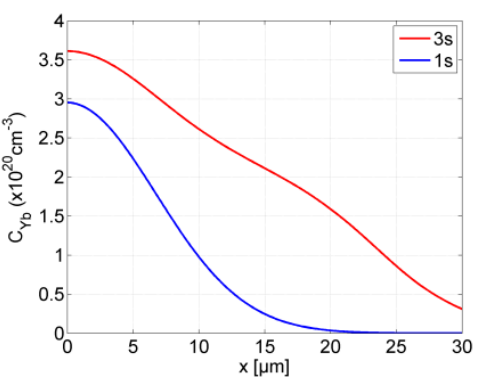

(b)
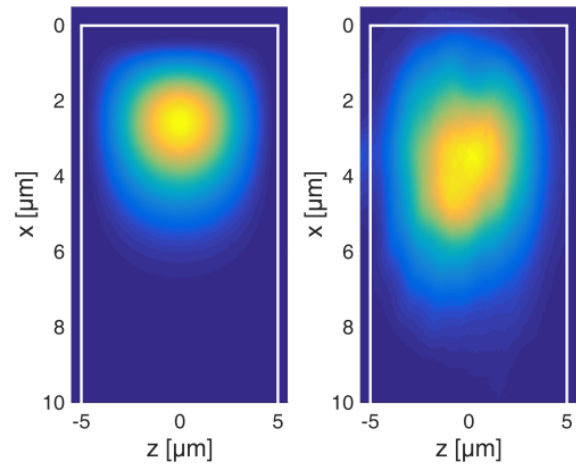

(c)

Figure 7. (a) Simulated $\mathrm{Yb}$ profile in $\mathrm{LiNbO}_{3}$ for the in-diffusion of two $22 \mathrm{~nm}$ thick layers evaporated under $\pm 60^{\circ}$ and in-diffused for $216 \mathrm{~h}$ at $1125^{\circ} \mathrm{C}$. (b) The Yb profile in x-direction in the middle of the ridge (red line). The results for a plane layer of $\mathrm{Yb}$ diffused in from the surface only are included as a blue line. (c) Simulated (left) and measured (right) intensity distribution for the fundamental mode at $980 \mathrm{~nm}$ for a $10 \mu \mathrm{m}$-wide ridge-waveguide formed by three-side Ti in-diffusion. 
Figure 7c shows the expected intensity distribution of the quasi-TE modes at $800 \mathrm{~nm}$ and the intensity distribution measured at $796 \mathrm{~nm}$. It is clearly visible that a good overlap between the $\mathrm{Yb}$ profile and the intensity distribution of the mode is achieved. The simulated concentration profiles shown in Figure $7 \mathrm{a}, \mathrm{b}$ prove that ridge waveguides can be almost homogeneously doped by three-side in-diffusion while avoiding any surface damage that might be caused by exceeding the maximum solubility of $\mathrm{Yb}$ in $\mathrm{LiNbO}_{3}$.

The transmission spectrum of such a $10 \mu \mathrm{m}$ wide and $2.2 \mathrm{~cm}$ long ridge waveguide was measured using unpolarized white light coupled into the waveguide by means of a $40 \times$ microscope objective. At the output facet, the transmitted light was collected and coupled into a spectrometer. To measure absorption as a function of polarization, a polarizer was placed in front of the collimator of the spectrometer. The measured absorption spectra ( $\pi$ and $\sigma$ polarization) show three main peaks at 918 , 956, and $980 \mathrm{~nm}$ (see Figure 8a), which is in good agreement with the absorption spectra reported for bulk-doped $\mathrm{Yb}: \mathrm{LiNbO}_{3}$ [22] and $\mathrm{Yb}: \mathrm{Ti}_{\mathrm{LiNbO}}$ channel waveguides [14]. The losses of the waveguide of $0.8 \mathrm{~dB} / \mathrm{cm}$ were determined at $1064 \mathrm{~nm}$ using the Fabry-Perot method. Fluorescence spectra ( $\pi$ and $\sigma$ polarization) were measured for pumping with a titanium-sapphire laser at $918 \mathrm{~nm}$. Figure $8 \mathrm{~b}$ shows the polarized fluorescence spectrum. In agreement with previously reported results for $\mathrm{Yb}: \mathrm{LiNbO}_{3}$ waveguides [14,20], we observed the expected four main peaks around 960, 980, 1008, and $1062 \mathrm{~nm}$.

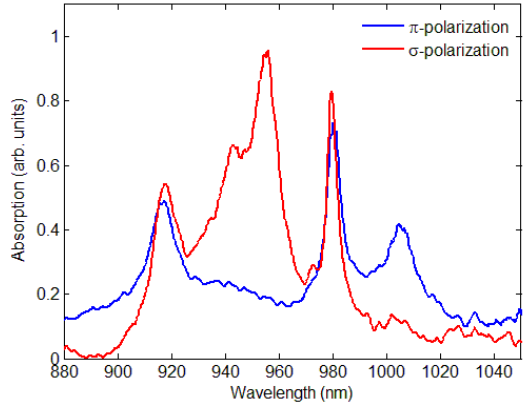

(a)

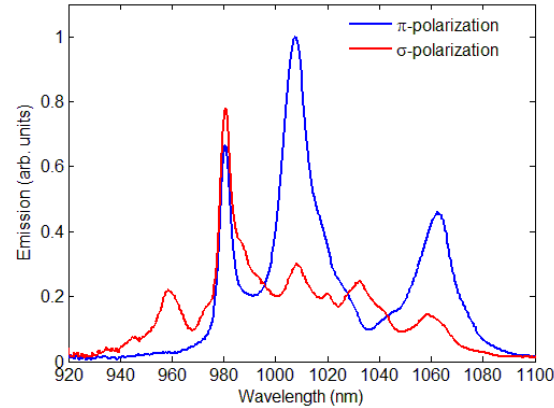

(b)

Figure 8. Polarization-dependent absorption (a) and fluorescence (b) spectrum of a $10 \mu \mathrm{m}$ wide and $2.2 \mathrm{~cm}$ long $\mathrm{Yb}: \mathrm{Ti}: \mathrm{LiNbO}_{3}$ ridge waveguide.

\section{Summary}

The diffusion of $\mathrm{Yb}$ in $\mathrm{LiNbO}_{3}$ can be described by Fick's law of diffusion. The experimental values determined in this work reveal an anisotropic diffusion coefficient with higher values for the diffusion along the crystallographic c-axis (z-axis). No anisotropy was found for the (maximum) solubility of $\mathrm{Yb}$ in $\mathrm{LiNbO}_{3}$. However, the solubility is temperature-dependent. When the diffusion reservoir is not exhausted, small grains of $\mathrm{Yb}$ remain on top of the surface, leading to high surface roughness, which has to be strictly avoided when fabricating optical waveguides. Absorption and fluorescence measurements for $\mathrm{Yb}$ diffusion-doped ridge waveguides are in good agreement with results published for volume-doped bulk substrates. These results are essential for the future development of efficient $\mathrm{Yb}$-based laser sources in $\mathrm{LiNbO}_{3}$ ridge waveguides.

Author Contributions: Investigation C.E.R., D.B., and S.S.; writing-original draft preparation, C.E.R.; writing-review and editing, D.B., S.S., and D.K.; supervision, D.K.; project administration, D.K.; funding acquisition, D.K. All authors have read and agreed to the published version of the manuscript.

Funding: This research was funded by Deutsche Forschungsgemeinschaft (grant DFG Ki482/17-1).

Conflicts of Interest: The authors declare no conflict of interest. 


\section{References}

1. Hu, H.; Ricken, R.; Sohler, W.; Wehrspohn, R.B. Lithium Niobate Ridge Waveguides Fabricated by Wet Etching. IEEE Photon Technol. Lett. 2007, 19, 417-419. [CrossRef]

2. Hu, H.; Ricken, R.; Sohler, W. Low-loss ridge waveguides on lithium niobate fabricated by local diffusion doping with titanium. Appl. Phys. A 2010, 98, 677-679. [CrossRef]

3. Volk, M.F.; Suntsov, S.; Rüter, C.E.; Kip, D. Low loss ridge waveguides in lithium niobate thin films by optical grade diamond blade dicing. Opt. Express 2016, 24, 1386-1391. [CrossRef]

4. Courjal, N.; Guichardaz, B.; Ulliac, G.; Rauch, J.-Y.; Sadani, B.; Lu, H.; Bernal, M.-P. High aspect ratio lithium niobate ridge waveguides fabricated by optical grade dicing. J. Phys. D Appl. Phys. 2011, 44, 305101. [CrossRef]

5. Gerthoffer, A.; Guyot, C.; Qiu, W.; Ndao, A.; Bernal, M.-P.; Courjal, N. Strong reduction of propagation losses in $\mathrm{LiNbO}_{3}$ ridge waveguides. Opt. Mater. 2014, 38, 37-41. [CrossRef]

6. Cai, L.; Wang, Y.; Hu, H. Low-loss waveguides in a single-crystal lithium niobate thin film. Opt. Lett. 2015, 40, 3013-3016. [CrossRef] [PubMed]

7. Becker, C.; Oesselke, T.; Pandavenes, J.; Ricken, R.; Rochhausen, K.; Schreiber, G.; Sohler, W.; Suche, H.; Wessel, R.; Balsamo, S.; et al. Advanced Ti:Er:LiNbO 3 waveguide lasers. IEEE J. Sel. Top. Quantum Electron. 2000, 6, 101-113. [CrossRef]

8. Lallier, E.; Pocholle, J.; Papuchon, M.; Grezes-Besset, C.; Pelletier, E.; De Micheli, M.; Li, M.; He, Q.; Ostrowsky, D. Laser oscillation of single-mode channel waveguide in $\mathrm{Nd}: \mathrm{MgO}: \mathrm{LiNbO}_{3}$. Electron. Lett. 1989, 25, 1491. [CrossRef]

9. De Micheli, M.; Lallier, E.; Grezes-Besset, C.; Pelletier, E.; Pocholle, J.P.; Li, M.J.; He, Q.; Papuchon, M.; Ostrowsky, D.B. Nd:MgO: $\mathrm{LiNbO}_{3}$ waveguide laser and amplifier. Opt. Lett. 1990, 15, 682-684. [CrossRef]

10. Di Paolo, R.E.; Cantelar, E.; Pernas, P.; Pedrola, G.L.; Cussó, F. Continuous wave waveguide laser at room temperature in Nd[sup 3+]-doped Zn:LiNbO[sub 3]. Appl. Phys. Lett. 2001, 79, 4088-4090. [CrossRef]

11. Siebenmorgen, J.; Calmano, T.; Petermann, K.; Huber, G.; Huber, G. Highly efficient Yb:YAG channel waveguide laser written with a femtosecond-laser. Opt. Express 2010, 18, 16035-16041. [CrossRef] [PubMed]

12. Okhotnikov, O.G.; Gomes, L.; Xiang, N.; Jouhti, T.; Grudinin, A.B. Mode-locked ytterbium fiber laser tunable in the 980-1070-nm spectral range. Opt. Lett. 2003, 28, 1522-1524. [CrossRef]

13. Malinowski, A.; Piper, A.; Price, J.H.V.; Furusawa, K.; Jeong, Y.; Nilsson, J.; Richardson, D. Ultrashort-pulse Yb3+-fiber-based laser and amplifier system producing >25-W average power. Opt. Lett. 2004, 29, 2073-2075. [CrossRef] [PubMed]

14. Jones, J.K.; De Sandro, J.P.; Hempstead, M.; Shepherd, D.P.; Large, A.C.; Tropper, A.C.; Wilkinson, J. Channel waveguide laser at $1 \mu \mathrm{m}$ in $\mathrm{Yb}$-indiffused $\mathrm{LiNbO}_{3}$. Opt. Lett. 1995, 20, 1477-1479. [CrossRef] [PubMed]

15. Fujimura, M.; Tsuchimoto, H.; Suhara, T. Yb:LiNbO 3 Annealed/Proton-Exchanged Waveguide Lasers Pumped by InGaAs Laser Diode at $980 \mathrm{~nm}$ Wavelength. Jpn. J. Appl. Phys. 2007, 46, 5447-5449. [CrossRef]

16. Pal, S.; Das, B.K.; Sohler, W. Photorefractive damage resistance in Ti:PPLN waveguides with ridge geometry. Appl. Phys. A 2015, 120, 737-749. [CrossRef]

17. Suntsov, S.; Rüter, C.E.; Kip, D. Er:Ti: $\mathrm{LiNbO}_{3}$ ridge waveguide optical amplifiers by optical grade dicing and three-side Er and Ti in-diffusion. Appl. Phys. B Laser Opt. 2017, 123, 118. [CrossRef]

18. Kip, D.; Brüske, D.; Suntsov, S.; Rüter, C.E. Efficient ridge waveguide amplifiers and lasers in Er-doped lithium niobate by optical grade dicing and three-side Er and Ti in-diffusion. Opt. Express 2017, 25, 29374.

19. Brüske, D.; Suntsov, S.; Rüter, C.E.; Kip, D. Efficient $\mathrm{Nd}: \mathrm{Ti}: \mathrm{LiNbO}_{3}$ ridge waveguide lasers emitting around $1085 \mathrm{~nm}$. Opt. Express 2019, 27, 8884-8889. [CrossRef]

20. Fujimura, M.; Tsuchimoto, H.; Suhara, T. Yb-diffused LiNbO/sub 3/ annealed/proton-exchanged waveguide lasers. IEEE Photon Technol. Lett. 2004, 17, 130-132. [CrossRef]

21. Amin, J.; Aust, J.; Veasey, D.; Sanford, N. Dual wavelength, 980 nm-pumped, Er/Yb-codoped waveguide laser in Ti:LiNbO 3 . Electron. Lett. 1998, 34, 456. [CrossRef]

22. Burns, G.; O'Kane, D.F.; Title, R.S. Optical and Electron-Spin-Resonance Spectra of $Y b 3+, N d 3+$, andCr3+in $\mathrm{LiNbO}_{3}$ and $\mathrm{LiTaO}_{3}$. Phys. Rev. 1968, 167, 314-319. [CrossRef]

(C) 2020 by the authors. Licensee MDPI, Basel, Switzerland. This article is an open access article distributed under the terms and conditions of the Creative Commons Attribution (CC BY) license (http://creativecommons.org/licenses/by/4.0/). 